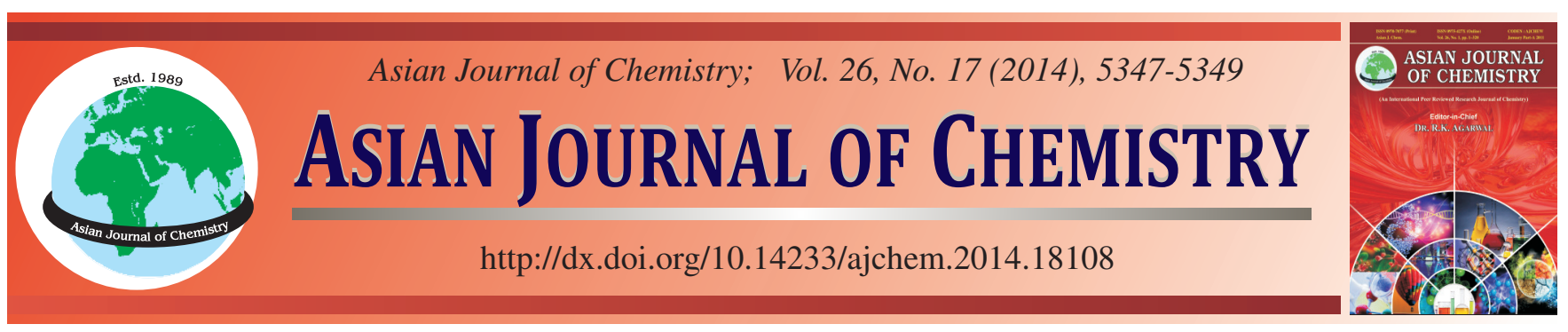

\title{
Corrosion Mechanism of 12Cr2NiWVA Cylinder Liners $\dagger$
}

Zhiling Peng* and Heming Zhao

College of Mechatronic Engineering, North University of China, Taiyuan 030051, Shanxi Province, P.R. China

*Corresponding author: E-mail: pengzhiling@ nuc.edu.cn

The corrosion mechanism of the inner surface of $12 \mathrm{Cr} 2 \mathrm{NiWVA}$ cylinders under high temperature and high pressure conditions has been investigated in this paper. The corrosion and SEM morphology on the inner cylinder surfaces were observed and the effects of nitriding, heat treatments and finish grinding were studied. By analyzing the corrosive ingredients and measuring section hardness, it revealed that the chromium content in the matrix is reduced during the nitride treatment on the inner surface. The oxidation, corrosion and wear resistance is reduced due to grinding on the finish and uneven temperatures during the heat treatment leads to decreased performance and deformation of the product increases.

Keywords: Corrosion mechanism, 12Cr2NiWVA, Cylinder liner, Heat corrosion.

\section{INTRODUCTION}

$12 \mathrm{Cr} 2 \mathrm{NiWVA}$ is a kind of special metal compound with good corrosion and heat resistance. It is used to make components such as high-powered engine cylinder liners after quenching, ion nitriding, gas nitriding and heat treatment $t^{1,2}$. A nitride layer consists of a surface compound layer and a sub-surface diffusion layer and can increase wear resistance, corrosion resistance and fatigue resistance ${ }^{3,4}$. An engine with a high working temperature makes heat corrosion of 12Cr2NiWVA cylinder liners inevitable ${ }^{3}$, which further effects the technical performance and life of the engine.

Heat corrosion of metal is the corrosion of the base metal at high temperatures in a gas environment and it is a serious surface corrosive of hot gas channel parts ${ }^{5,6}$. Fuel, dust, water vapor, impurities and various ions, thermodynamics and fluid dynamics produce heat corrosion factors ${ }^{7,8}$. It can cause varying degrees of corrosion pits and residues under certain conditions and even cause component failure ${ }^{9,10}$. Therefore, research on corrosion mechanisms can provide the necessary theoretical basis for retarding corrosion and improving component reliability.

\section{EXPERIMENTAL}

A $12 \mathrm{Cr} 2 \mathrm{NiWVA}$ cylinder liner was used after quenching and nitriding. The liner works in pressurized gas environments with a temperatures of $1200{ }^{\circ} \mathrm{C}$ and a pressure of $28 \mathrm{MPa}$. In order to ensure the dimensional accuracy and a smooth surface finish of the cylinder liner, the inner surface goes through a grinding process, as shown in Fig. 1. Research content and the corresponding equipments are listed in Table- 1 .

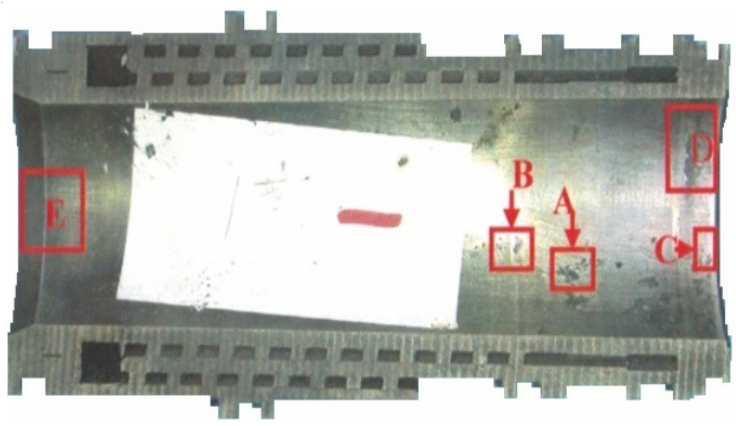

Fig. 1. 12Cr2NiWVA, cylinder liner inner surface

\begin{tabular}{cc} 
& TABLE-1 \\
RESEARCH CONTENTS AND EQUIPMENT \\
\hline Research content & Equipment \\
\hline Corroded areas & OLYMPUS SZX10 Stereomicroscope \\
Corrosion & SEM-6510 \\
Nitriding thickness & OLYMPUS BX51M \\
& Metallographic microscope \\
Microstructure & OLYMPUS BX51M \\
& Metallographic microscope \\
Section hardness & HX-1000TM/LCD \\
& Micro hardness tester \\
\hline
\end{tabular}




\section{RESULTS AND DISCUSSION}

\section{Analysis of observation point}

Analysis of point A: The microstructure of point $\mathrm{A}$ are shown in Figs. 2 and 3. In Fig. 2, part a and b are two large corrosion pits which are funnel-shaped, the smaller on the outer surface, the larger on the inner surface and approximately $1 \mathrm{~mm}$ deep. Fig. 3 shows the pits have been covered with cracking corrosion residues and spherical metal bodies of the arrow that are formed of cooling metal splashing into the corrosion pits. It is metal melt when molybdenum wire EDM wire cutting and is not the original sample $e^{9,10}$.

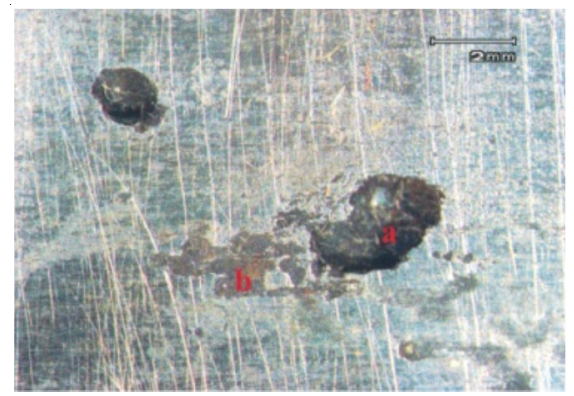

Fig. 2. Enlarged view of the corrosion pits

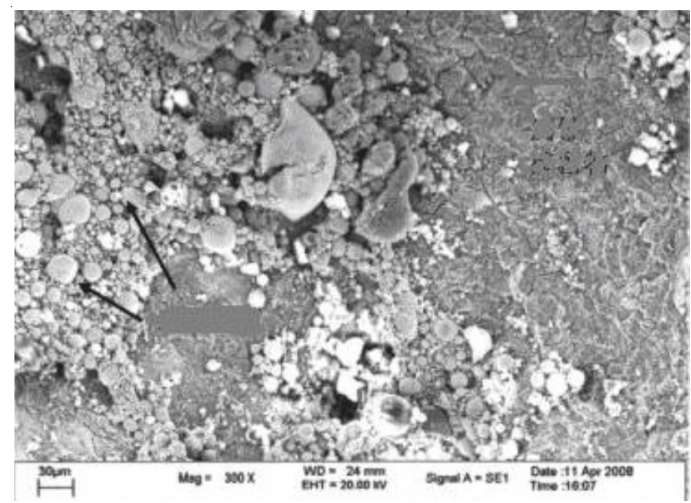

Fig. 3. SEM of the inner surface topography

Analysis of point D: Microscopic views are shown in Figs. 4 and 5. Fig. 4 shows the microstructure is composed of massive ferrite and tempered sorbite. Oxidized corrosion is seen along the boundaries of the ferrite grains. In Fig 5, the nitrided layer also contains a small amount of granular nitrogencarbon compounds. It shows a serious shortage of quenching temperature during the heat treatment.

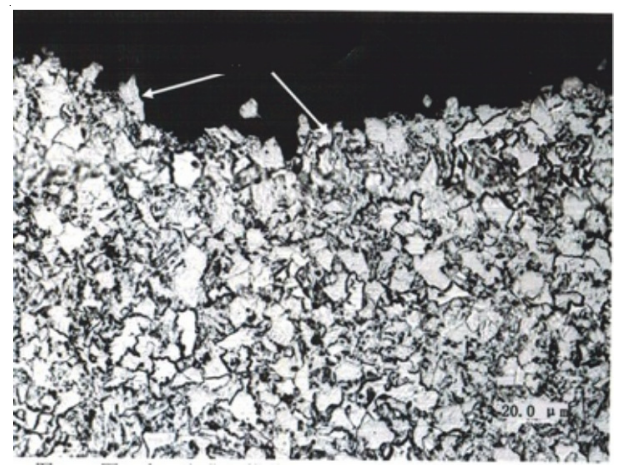

Fig. 4. D site along sectional directional light

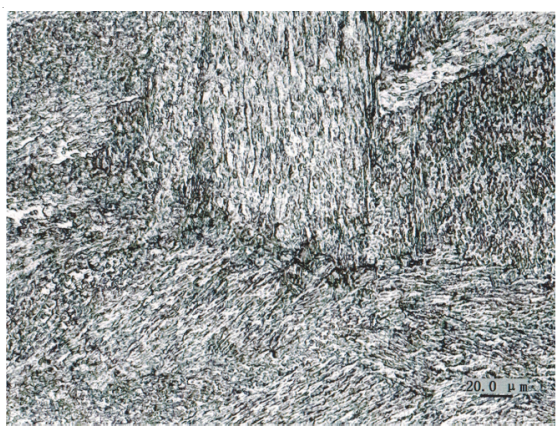

Fig. 5. D section of the site shows the nitrided layer along the cylinder jacket

Analysis of point E: Microscopic views are shown in Figs. 6 and 7. In Fig. 6, a nitrided area of the cylinder liner surface shows coarse granular bainite and granular nitride. In Fig. 7, it shows thick sorbite to keep the original plate martensite and a small amount of bainite. It shows the site is made up of grossly overheated compounds from high quenching temperatures during the heat treatment.

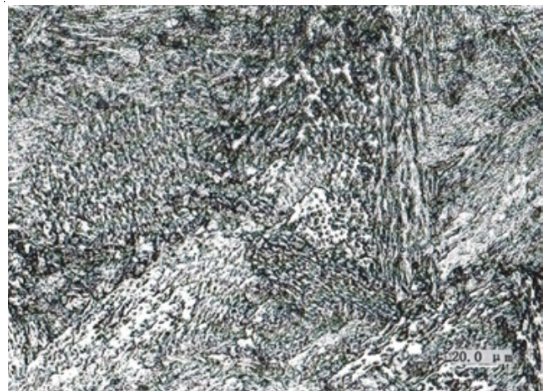

Fig. 6. E section of the site shows the nitrided layer along the cylinder jacket

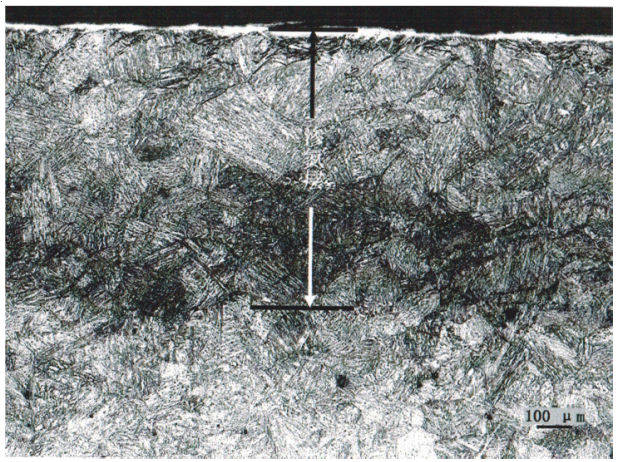

Fig. 7. E micrograph of the outer parts of the cylinder liner

Analysis of corrosive component: In Fig. 8, EDS analysis of the corrosion in a cross-section of the metal shows the cylinder liner surface suffers from heat corrosion because of the chemical reaction with $\mathrm{S}, \mathrm{O}, \mathrm{Ca}$ and other elements in high temperature and high pressure gas. The corrosion residue is metal oxide and its regional chemical composition is shown in Table- 2 .

Nitrided layer depth measurement: The hardness gradient method is adopted to measure the depth of the nitrided layer ${ }^{11,12}$. A cross-section of E site was selected to analyze both the outer surface and the inner surface of the cylinder liner. The hardness tests results are shown in Table- 3 . 


\begin{tabular}{|c|c|c|c|c|c|c|c|c|c|}
\hline \multicolumn{10}{|c|}{$\begin{array}{c}\text { TABLE-2 } \\
\text { EDS COMPOSITION ANALYSIS OF CORROSION PRODUCTS }\end{array}$} \\
\hline \multirow{2}{*}{\multicolumn{2}{|c|}{ Regional }} & \multicolumn{8}{|c|}{$\begin{array}{c}\text { Chemical composition } \\
\end{array}$} \\
\hline & & $\mathrm{O}$ & $\mathrm{Si}$ & $\mathrm{Cr}$ & $\mathrm{Mn}$ & $\mathrm{Fe}$ & $\mathrm{Ni}$ & Мо & W \\
\hline \multirow{2}{*}{1} & wt $\%$ & - & 0.63 & 2.69 & 0.69 & 94.98 & 1.01 & - & - \\
\hline & at $\%$ & - & 1.24 & 2.87 & 0.70 & 94.24 & 0.96 & - & - \\
\hline \multirow{2}{*}{2} & wt $\%$ & 23.51 & 1.11 & 12.04 & 0.69 & 52.71 & - & 2.15 & 7.79 \\
\hline & at $\%$ & 53.20 & 1.43 & 8.39 & 0.46 & 34.18 & - & 0.81 & 1.53 \\
\hline \multirow{2}{*}{3} & wt $\%$ & - & 0.58 & 2.31 & 0.85 & 95.14 & 1.12 & - & - \\
\hline & at $\%$ & - & 1.14 & 2.46 & 0.85 & 94.48 & 1.06 & - & - \\
\hline
\end{tabular}

\begin{tabular}{ccccccccccc}
\multicolumn{10}{c}{ TABLE-3 } \\
\multicolumn{10}{c}{ HARDNESS TEST RESULTS OF SUBSTRATE DIRECTION } \\
\hline & $\begin{array}{c}\text { Test site } \\
\text { (E) }\end{array}$ & 1 & 2 & 3 & 4 & 5 & 6 & $\begin{array}{c}\text { Matrix } \\
\text { hardness }\end{array}$ & $\begin{array}{c}\text { Nitrided layer } \\
\text { thickness (mm) }\end{array}$ \\
\hline Inner & Distance from the surface $(\mathrm{mm})$ & 0.03 & 0.21 & 0.34 & 0.46 & 0.58 & - & - & 0.58 \\
surface & HV0.3 & 722.4 & 684.9 & 517.1 & 366.6 & 341.5 & - & 306.1 & 0.1 \\
\hline $\begin{array}{c}\text { Outer } \\
\text { surface }\end{array}$ & Distance from the surface $(\mathrm{mm})$ & 0.06 & 0.16 & 0.32 & 0.60 & 0.79 & 0.83 & - & 0.83 \\
\hline
\end{tabular}

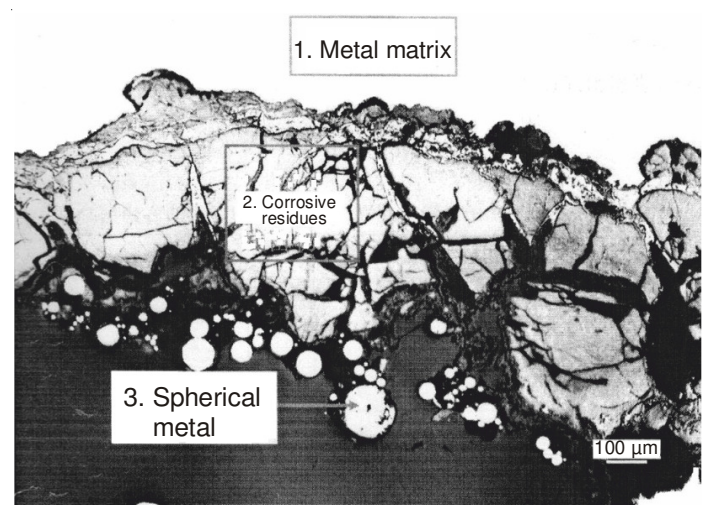

Fig. 8. EDS composition of corrosion products

Hardness tests results show the nitriding treatment was successful. But due to grinding, the nitride layer on the outside surface is much thicker than the layer on the inner surface.

\section{Conclusion}

- Nitriding improves the wear resistance of the cylinder surface liner, but corrosion resistance can be reduced because of chromium nitride that is generated. The effects of high temperature gas can produce shallow pits from oxidation and corrosion. it is prone to gas vortex in corrosion pits. Increased oxidation and corrosion also leads to the development of deep and funnel-shaped corrosion pits.

-When nitriding, the formed nitrogen compound has good wear and corrosion resistance to oxidation. But in order to ensure that the inner surface of the cylinder liner is the appropriate size and the surface is bright and clean, finish grinding is required. However, this process can make the nitrogen compound layer thin or non-existent, resulting in oxidation wear and reduced corrosion resistance.

- When nitriding, the nitrogen compound has good wear and corrosion resistance to oxidation. But in order to ensure that the inner surface of the cylinder liner is the appropriate size and the surface is bright and clean, finish grinding is required. However, this process can make the nitrogen compound layer thiner or disappears, resulting in oxidation wear and reduced corrosion resistance.

In summary, chromium, aluminum and other metal compounds can formed after nitriding which can effectively improve the oxidation and corrosion resistance of the cylinder liner.

\section{REFERENCES}

1. Z.T. Huang, W.H. Tian and Y.A. Su, Heat Treatment Metals, 35, 101 (2010).

2. M. Kaur, H. Singh and S. Prakash, Therm. Spray Technol., 18, 619 (2009).

3 X.M. Huang, Internal Combustion Engines, 1, 51 (2006).

4. K. Weulersse, G. Moulin, P. Billard and G. Pierotti, Mater. Sci. Forum, 461-464, 973 (2004)

5. Z.H. Na, Heilong Jiang Jiao Tong Keji, 26, 15 (2004).

6. T.S. Sidhu, S. Prakash and R.D. Agrawal, Surf. Coat. Technol., 201, 792 (2006).

7. S.W. Li, L.F. Huang and Q.L. Meng, Machining Mold, 4, 63 (2013).

8. N. Espallargas, J. Berget, J.M. Guilemany, A.V. Benedetti and P.H. Suegama, Surf. Coating Technol., 202, 1405 (2008).

9. L. Chen, Paper Sci. Technol., 31, 110 (2012).

10. R.A. Mahesh, R. Jayaganthan and S. Prakash, Mater. Process. Technol., 209, 3501 (2009).

11. G.Z. Shen, Trans. Chinese Soc. Agric. Machinery, 44, 261 (2013).

12. I. Gurrappa, A.K. Gogia and I.V.S. Yashwanth, J. Surface Eng. Mater. Adv. Technol., 1, 144 (2011). 